\title{
Faecal examination and PCR to detect Strongyloides venezuelensis in experimentally infected Lewis rats
}

\author{
Nelson Mendes Marra', Fernanda Chiuso-Minicucci², Gabriel Capella Machado', \\ Sofia Fernanda Gonçalves Zorzella-Pezavento², Thaís Graziela Donegá França², \\ Larissa Lumi Watanabe Ishikawa ${ }^{2}$, Alessandro FT Amarante ${ }^{1}$, Alexandrina Sartori ${ }^{2}$, \\ Mônica RV Amarante ${ }^{1 /+}$
}

\author{
${ }^{1}$ Departamento de Parasitologia ${ }^{2}$ Departamento de Microbiologia e Imunologia, Instituto de Biociências, \\ Universidade Estadual Paulista, 18618-000 Botucatu, SP, Brasil
}

\begin{abstract}
More sensitive methodologies are necessary to improve strongyloidiasis diagnosis. This study compared the sensitivities of the McMaster modified technique and polymerase chain reaction (PCR) assays, both performed in faecal samples. Lewis rats were subcutaneously infected with 4,000, 400 or 40 infective third-stage larvae, considered as high, moderate or low infection, respectively. Seven days later, they were euthanized to count adult nematodes recovered from the small intestine. Stool samples were used to count the number of eggs per gram (EPG) of faeces and to detect parasite DNA by PCR performed with a species and a genus primer pair. The sensitivity of these assays depended upon parasite burden and the primer specificity. All assays presented 100\% sensitivity at the highest parasite load. In the moderate infection, EPG and PCR with the genus primer maintained $100 \%$ specificity, whereas $P C R$ sensitivity with the species primer decreased to $77.7 \%$. In low infection, the sensitivity was $60 \%$ for EPG, $0 \%$ for $P C R$ with the species primer and $90 \%$ for PCR done with the genus primer. Together, these results suggest that PCR with a genus primer can be a very sensitive methodology to detect Strongyloides venezuelensis in faeces of Lewis rats infected with very low parasite burden.
\end{abstract}

Key words: Strongyloides venezuelensis - faecal egg counts - DNA - PCR - diagnosis - Lewis rats

Strongyloides stercoralis infects 30 million people in 70 countries (Siddiqui \& Berk 2001). This parasitosis can occur without symptoms, as a disseminated infection or potentially fatal hyperinfection (Concha et al. 2005, Vadlamudi et al. 2006, Al-Hasan et al. 2007). Diagnosis of strongyloidiasis is usually based on detection of larvae in stool samples. However, in the majority of uncomplicated cases of strongyloidiasis, the intestinal worm load is very low and the output of larvae is minimal (Liu \& Weller 1993). This scenario is hampering diagnosis, which leads to an underestimation of infection rates. Therefore, the development and validation of more sensitive assays to detect light helminth infections are required (Dreyer et al. 1996, Uparanukraw et al. 1999, Siddiqui \& Berk 2001).

Strongyloides venezuelensis is a nematode of wild rodents that is frequently used as a model organism to unravel host-parasite interactions, molecular aspects during infection, the efficacy of new therapies and many immunological characteristics (Machado et al. 2007, 2009). S. venezuelensis evokes similar innate and acquired immune responses in mice as $S$. stercoralis, but

Financial support: FAPESP, FUNDUNESP

+ Corresponding author: monicarv@ibb.unesp.br

Received 17 June 2009

Accepted 18 December 2009 is safer for laboratory manipulation. This nematode has also been used to standardise new immunological techniques to optimise human strongyloidiasis diagnosis (Machado et al. 2008, 2009).

Polymerase chain reaction (PCR) has been a highly sensitive method to detect pathogens in light infections (Weiss 1995). Pontes et al. (2003), for example, demonstrated that PCR was much more sensitive than the KatoKatz technique (Katz et al. 1972) to detect Schistosoma mansoni in human faeces. Similar results were observed in S. mansoni infected mice (Sandoval et al. 2006). Interestingly, PCR has been associated with higher sensitivity than classical parasitological methods during infections with lower intensity (Wongratanacheewin et al. 2001). Verweij et al. (2009) evaluated the molecular diagnosis of $S$. stercoralis in faecal samples using real-time PCR. The authors demonstrated that this methodology could be a useful alternative to the commonly used Baermann method, offering a two-fold increase in the detection rate.

In this study we compared the sensitivities of the McMaster modified technique and PCR assays, both performed in faecal samples from Lewis rats infected with three different parasite inocula.

\section{MATERIALS AND METHODS}

Animals - Female and male Lewis rats (6-weeksold) were obtained from a colony maintained in the Animal Facility from the Departamento de Microbiologia e Imunologia, Universidade Estadual Paulista, Botucatu, São Paulo, Brazil. Rats received sterilised food and water ad libitum and were manipulated in 
compliance with the ethical guidelines adopted by the Colégio Brasileiro de Experimentação Animal, being the experimental protocol approved by the local Ethical Committee (protocol 45/07).

Parasite and experimental infection - The $S$. venezuelensis strain was isolated from wild rats in 1980 and has been maintained in Wistar rats. For the experimental infections, infective $S$. venezuelensis third-stage larvae (L3s) were obtained according to Amarante and Oliveira-Sequeira (2002).

To establish a model mimicking the different degrees of human infections, rats were experimentally infected with a high number of infective larvae $(4,000 \mathrm{~L} 3 \mathrm{~s})$, a moderate number (400 L3s) or a low number (40 L3s) (Nakai \& Amarante 2001).

Two groups with 10 animals (5 males and 5 females) each were inoculated subcutaneously with 4,000, 400 or $40 \mathrm{~S}$. venezuelensis L3s. However, one female animal infected with $400 \mathrm{~L} 3 \mathrm{~s}$ died of undetermined cause during the trial. Therefore, this group remained with nine rats. The animals were euthanized seven days after the infection.

Infection intensity was determined by counting the number of eggs per gram (EPG) of faeces by a McMaster modified technique (Ueno \& Gonçalves 1998) and by counting the number of parasitic female worms found in the first third portion of the small intestine (Nakai \& Amarante 2001).

DNA extraction, primer design and genotyping by $P C R$ - DNA from faecal samples was extracted with QIAamp DNA stool mini kit. QIAamp DNA mini kit (QIAGEN, Hilden, Germany) was used to extract DNA from $S$. venezuelensis L3 larvae, the spleen of a noninfected rat and an adult specimen of Syphacia muris, a nematode commonly recovered from rats. S. venezuelensis L3 larval DNA was used as a positive control to detect this nematode and to determine PCR sensitivity. S. muris and non-infected rat DNA samples were also used as controls for PCR to identify the origin of both similar and divergent bands amplified by the genus primer. A blank tube (PCR mix without DNA template) was used as a negative control to indicate absence of environmental contamination.

The species oligonucleotide primer pair (Forward 5'-TTAGTGGTGCGTGGATTTGA-3' and Reverse 5'-ATGTGGAGCCGTTTATCAGG-3') was designed using the Primer-BLAST program and a $S$. venezuelensis partial 18S rDNA sequence obtained at the GenBank (accession AJ417026). Primer3 software program (Rozen \& Skaletsky 2000) was employed to design PCR primer pairs that were submitted to BLAST and searched against Homo sapiens, Rattus norvegicus, S. venezuelensis, Strongyloides spp and S. muris genome sequences. The genus primer pair, SSUA and SSU22R, amplifies the small subunit ribosomal RNA gene and was described by Dorris et al. (2002) to analyse several species within the genus Strongyloides.

PCR were performed in the My cycler (Bio-Rad, Hercules, CA, USA) and Gene Amp PCR System $9700^{\circledR}$ (Applied Biosystems, Foster City, CA, USA), thermocy- clers. PCR mixtures included $10 \mathrm{mM}$ dNTPs, $0.4 \mathrm{mM}$ each primer, $1.5 \mathrm{mM} \mathrm{MgCl}_{2}, 50 \mathrm{mM} \mathrm{KCl}, \mathrm{pH} 8.3$, dNTP, $0.5 \mathrm{U}$ of Taq polymerase ${ }^{\circledR}$ (GE Healthcare, Bucks, UK) and $100 \mathrm{ng}$ of genomic DNA in a $10 \mu \mathrm{L}$ reaction. The PCR conditions included initial denaturation at $95^{\circ} \mathrm{C}$ for $5 \mathrm{~min}$, followed by 40 cycles at $95^{\circ} \mathrm{C}$ for $30 \mathrm{sec}$ (denaturation) $60^{\circ} \mathrm{C}$ at $30 \mathrm{sec}$ (annealing for both primer pairs), extension at $72^{\circ} \mathrm{C}$ for $30 \mathrm{sec}$ and a final extension at $72^{\circ} \mathrm{C}$ for $7 \mathrm{~min}$. PCR products were then analysed by electrophoresis on $2 \%$ agarose gels in $1 \mathrm{x}$ TAE buffer containing ethidium bromide, photographed under UV light and quantitation of amplification products was carried out by the Infinity-Capt ${ }^{\circledR}$ software version 15.01 and the Infinity $3000 \mathrm{WL} / \mathrm{LC} / 26 \mathrm{M}^{\circledR}$ image capture system (Vilber Lourmat, Marne-la-Valée, France). Both primer pairs were typed twice with all DNA samples and scored independently to increase the accuracy of results. Ambiguous results were typed a third time.

Statistical analysis - Pearson's correlation coefficient $(r)$ was determined between worm burden and FEC (log transformed data). The comparison between the techniques sensitivity used to detect $S$. venezuelensis was evaluated by the Fisher Exact Test. Significance level was $\mathrm{p}<0.05$.

\section{RESULTS}

The number of parasites recovered from the small intestine of Lewis rats infected with $4,000,400$ or 40 L3s was $2813.0 \pm 668.0,216.4 \pm 81.2$ and $7.3 \pm 5.6$, respectively. The number of EPG also depended upon the initial infecting dose and was $24690 \pm 24170,3533 \pm$ 2648 and $60.0 \pm 51.6$ EPG. These two variables showed a very high correlation coefficient $(r=0.893 ; \mathrm{p}<0.001)$ as depicted in Fig. 1.

PCR assays were initially performed with DNA samples extracted from S. venezuelensis larvae. Species and genus primer pairs allowed the amplification of product bands of sizes 198 and a $340 \mathrm{bp}$, respectively (not shown).

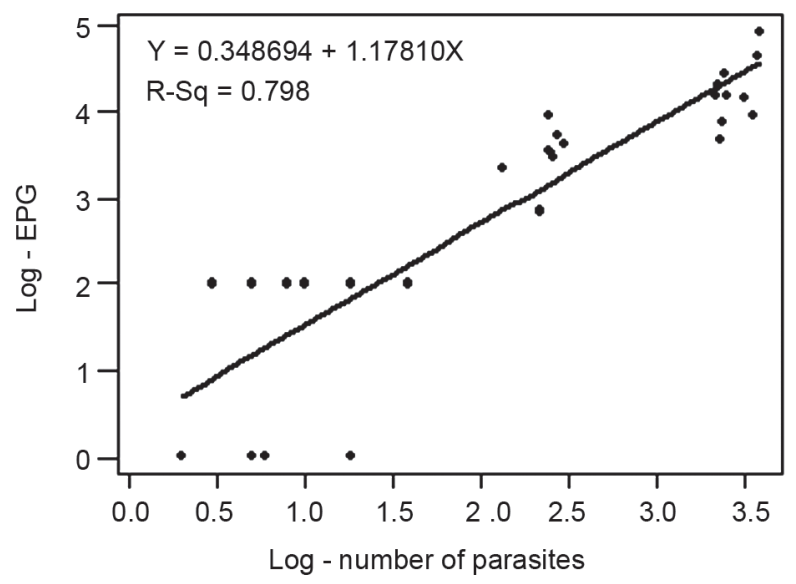

Fig. 1: relationship between counting the number of eggs per gram (EPG) of feces and number of parasites recovered from the small intestine in Lewis rats inoculated with 4,000, 400 or 40 infective larvae of Strongyloides venezuelensis. 
Both primer pairs were able to detect parasite DNA in the faecal samples obtained from all animals of the experimental group infected with 4,000 L3s, as can be observed by the very clear bands shown in Fig. 2. These findings coincided with the presence of parasite eggs in their respective faecal samples. The genus primer pair was also able to detect a $420 \mathrm{bp}$ band from DNA samples obtained from the spleen of non-infected rats, as seen in Fig. 2, Lane 2. As S. muris is frequently found in the large intestine of laboratory rodents without any clinical manifestation, a DNA sample from this nematode was also included as a control. In this case, the genus primer pair amplified a $380 \mathrm{bp}$ band, thus different from the band representing $S$. venezuelensis. The difference between these two primer pairs performance appeared with lower parasite burden. In the case of infection with 400 L3s larvae, the species primer pair detected $S$. venezuelensis DNA in seven out of eight DNA samples analysed. One sample was lost during the procedure. On the other hand, the genus primer pair amplified the $S$. venezuelensis 340 bp band in all nine samples analysed. In addition of this discrete numerical difference, the bands amplified with the genus primer pair were much more intense, as shown in Fig. 3. In this group parasite eggs were detected in all samples evaluated.

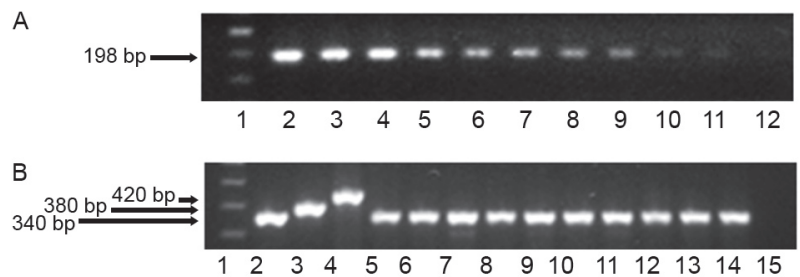

Fig. 2: Strongyloides venezuelensis PCR amplification from fecal samples of Lewis rats infected with 4,000 L3. A: specific primer (198 bp): Lane 1: 50 bp ladder (GE Healthcare); 2-11: 198 bp - DNA from fecal samples - $S$. venezuelensis DNA; 12: negative control; B: genus primer (340 bp): 1: 100 bp ladder (GE Healthcare); 2-4: PCR controls; 2: 340 bp (S. venezuelensis L3 DNA); 3: 380 bp (Syphacia muris DNA); 4: 420 bp (Rattus norvegicus DNA); 5-14: 340 bp - DNA from fecal samples; 15: negative control.

A
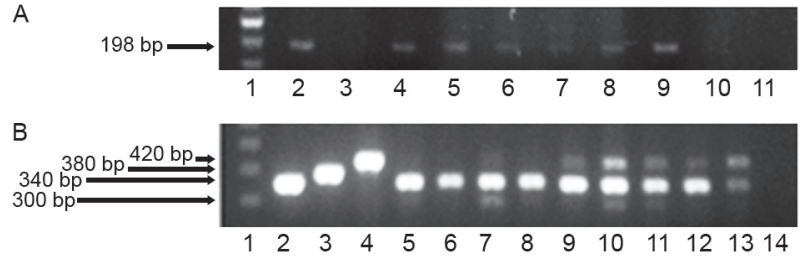

Fig. 3: Strongyloides venezuelensis PCR amplification from fecal samples of Lewis rats infected with $400 \mathrm{~L} 3$. A: specific primer (198 bp): Lane 1: 50 bp ladder (GE Healthcare); 2, 4-9: 198 bp - DNA from fecal samples - S. venezuelensis DNA. 3, 10: no amplification; 11: negative control; B: genus primer (340 bp): 1: 100 bp ladder (GE Healthcare); 2-4: PCR controls; 2: 340 bp (S. venezuelensis L3 DNA); 3: 380 bp (Syphacia muris DNA); 4: 420 bp (Rattus norvegicus DNA); 5-13: DNA from fecal samples - $340 \mathrm{bp} ; 9-13: 420 \mathrm{bp} ; 7,10,11: 300 \mathrm{bp}$ (unknown band); 14: negative control.
Differences in PCR sensitivity became clear in the animals submitted to the lowest parasite burden. The species primer pair did not detect parasite DNA in any of the 10 evaluated samples from rats infected with $40 \mathrm{~L} 3$ larvae. In contrast, the genus primer pair amplified the $340 \mathrm{bp}$ S. venezuelensis band in nine out of 10 samples analysed (Fig. 4, Lanes 5, 7-14).

This higher sensitivity was, however, associated with a loss in specificity, characterised by the appearance of other amplification bands of 300, 380 and $420 \mathrm{bp}$. Parasite eggs were detected in six out of 10 animals of this experimental group (Table).

A comparative analysis of sensitivity was done among EPG and the two PCR tests. As can be observed at Table, the three tests exhibited an equal $100 \%$ sensitivity in the highest parasite burden. PCR sensitivity with the species primer pair decreased to $77.7 \%$ in animals infected with $400 \mathrm{~L} 3 \mathrm{~s}$, whereas EPG and PCR with the genus primer pair maintained $100 \%$ sensitivity. The most striking difference among these tests was observed with the lowest parasite burden. In this case the sensitivity was $60 \%$ for EPG, $0 \%$ for PCR performed with the species primer pair and $90 \%$ for PCR done with the genus primer pair.

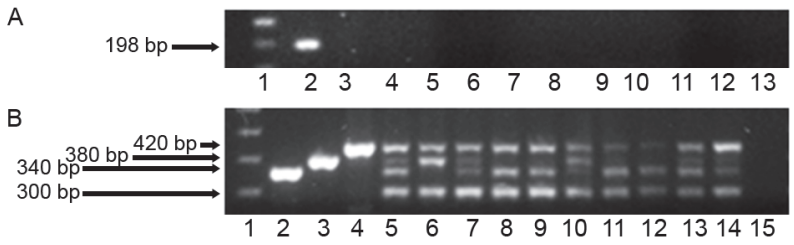

Fig. 4: Strongyloides venezuelensis PCR amplification from fecal samples of Lewis rats infected with 40 L3. A: specific primer (198 bp): Lane 1: 50 bp ladder (GE Healthcare); 2: positive control-198 bp (S. venezuelensis L3 DNA); 3-12: no amplification; 13: negative control; B: genus primer (340 bp): 1: 100 bp ladder (GE Healthcare); 2-4: PCR controls; 2: 340 bp (S. venezuelensis L3 DNA); 3: 380 bp (Syphacia muris DNA); 4: 420 bp (Rattus norvegicus DNA); 5, 7-14: 340 bp; 5-7, 10, 13, 14: $380 \mathrm{bp}$; 5-14: $420 \mathrm{bp}$ and $300 \mathrm{bp}$ (unknown band); 15: negative control.

\section{DISCUSSION}

The development of more sensitive tests for the diagnosis of strongyloidiasis is highly required because it affects an estimated 100 million people worldwide (Evering \& Weiss 2006) and because the popular Kato-Katz method gives only a low sensitivity with direct faecal smears (Steinmann et al. 2007).

As PCR has been described as a very sensitive technique, we compared the sensitivity between this methodology and the classical determination of EPG. Lewis rats were inoculated with 4,000, 400 or $40 \mathrm{~S}$. venezuelensis L3 larvae and EPG and PCR were performed in stool samples. In the present study we demonstrated that differences in sensitivity between these two techniques depend upon parasite burden and identity of the primer pairs. At the highest parasite load (4,000 L3s), 
TABLE

Fecal examination by McMaster modified technique and polymerase chain reaction (PCR) sensitivity, using the specific and the genus oligonucleotide primers with DNA from fecal samples of Lewis rats infected with 4,000, 400 or 40 infective larvae (L3) of Strongyloides venezuelensis

\begin{tabular}{|c|c|c|c|c|c|c|c|}
\hline \multirow[b]{3}{*}{ L3 infection } & \multirow{3}{*}{$\begin{array}{c}\text { Samples } \\
\mathrm{n}\end{array}$} & \multirow{2}{*}{\multicolumn{2}{|c|}{$\begin{array}{c}\text { McMaster modified } \\
\text { technique }\end{array}$}} & \multicolumn{2}{|c|}{$\begin{array}{c}\text { PCR } \\
\text { (specific primer) }\end{array}$} & \multicolumn{2}{|c|}{$\begin{array}{c}\text { PCR } \\
\text { (genus primer) }\end{array}$} \\
\hline & & & & Sen & & Sen & \\
\hline & & Positive & $(\%)$ & Positive & $(\%)$ & Positive & $(\%)$ \\
\hline 4,000 & 10 & 10 & 100 & 10 & 100 & 10 & 100 \\
\hline 400 & 9 & 9 & 100 & 7 & 77.7 & 9 & 100 \\
\hline 40 & 10 & 6 & $60^{a}$ & 0 & $0^{b}$ & 9 & $90^{a}$ \\
\hline
\end{tabular}

$a, b$ : significant difference by the Exact Fisher Test $(\mathrm{p}<0.05)$.

EPG and both PCR assays presented the same sensitivity $(100 \%)$. However, as the parasite burden decreased, EPG and PCR with the species primer pair lost sensitivity. Unexpectedly, this was even more accentuated in PCR than in the classical EPG. It is important to stress, however, that PCR sensitivity with the genus primer pair was still $100 \%$ in samples from animals infected with $400 \mathrm{~L} 3 \mathrm{~s}$, considered a moderate degree of infection, as described by Nakai and Amarante (2001). At the lowest parasite burden (40 L3s) PCR with the genus primer presented the highest degree of sensitivity, able to detect $S$. venezuelensis DNA in $90 \%$ of the analysed samples. In this case, sensitivity was $60 \%$ and $0 \%$ for EPG and PCR with the species primer, respectively. Even though a direct comparison with the literature is not possible due to differences in the experimental model and design, the described findings are similar to already published data in this field (Wongratanacheewin et al. 2001, Pontes et al. 2003, Sandoval et al. 2006).

A high correlation coefficient between worm burden and EPG were observed in this study, in agreement with Tamura (1993), Taira et al. (1995) and Nakai and Amarante (2001), who performed analyses with the same parasite, but with different rat strains and inoculum doses.

Besides the contribution of a more sensitive method in strongyloidiasis diagnosis, these findings also highlight the outstanding relevance of primer pair characteristics. In this case, the species primer pair did not show the expected higher sensitivity.

Considering the fact that PCR standardisation with DNA extracted from $S$. venezuelensis L3s was extremely sensitive $(0.8 \mathrm{ng} / \mu \mathrm{L})$, a much better performance was expected for the species primer pair. We could, for example, speculate that components present in the stool samples were somehow inhibiting this reaction. This effect was more noticeable in samples with lower parasite burden (e.g. in the presence of lesser amounts of parasite DNA). The findings of Oikarinen et al. (2009) support this hypothesis. These authors demonstrated that PCR inhibitors are relatively common in stool samples and that they can strongly influence the results of PCR assays. This possibility could be further investigated, for example, by testing the effect of adding faeces samples to known amounts of $S$. venezuelensis L3 DNA.
The genus primer pair was used concomitantly with the species pair because it was originally employed for analyzing species within the genus Strongyloides (Dorris et al. 2002) and performed with better sensitivity. However, it was associated with the appearance of bands other than the specific $340 \mathrm{bp}$ band. One of them was unknown (300 bp), the other was identified as $R$. norvegicus (420 bp) and another one as $S$. muris (380 bp). The appearance of several bands could have occurred because the genus primer amplified a ubiquitous region of the small subunit ribosomal RNA gene instead of a nematode-specific region, as expected and it also could be due to DNA competition for PCR amplification in mixed samples. Kreike and Lehner (1995) demonstrated pronounced DNA competition in PCR assays with forensic mixed samples.

One explanation for the presence of the $380 \mathrm{bp}$ band (S. muris) in faecal samples from the group infected with $40 \mathrm{~L} 3 \mathrm{~s}$ could be the housing of these animals in a conventional animal facility where the sanitary conditions standards are less rigorous. Pinto et al. (2001) described $S$. muris as a nematode parasite of rats and Gilioli et al. (2000) observed a prevalence of $80 \%$ of this parasite in a study performed to evaluate sanitary conditions within Brazilian animal facilities. Despite these additional bands, the $340 \mathrm{bp}$ band specific for S. venezuelensis DNA was undoubtedly present.

To the best of our knowledge, this was the first study to detect high, moderate or low experimental infection by $S$. venezuelensis in Lewis rats by faecal examination, parasite counting and PCR. These results indicated that the PCR assay employing the genus primer pair (Dorris et al. 2002) was more sensitive than EPG, primarily in light infections. This methodology could be applied in association with faecal examination in epidemiological studies to improve the diagnosis of strongyloidiasis, especially in hosts with small worm burden (e.g. with undetectable number of eggs or larvae in faeces and without clinical symptoms of infection).

\section{REFERENCES}

Al-Hasan MN, McCormick M, Ribes JA 2007. Invasive enteric infections in hospitalized patients with underlying strongyloidiasis. $\mathrm{Am}$ J Clin Pathol 128: 622-627. 
Amarante AFT, Oliveira-Sequeira TCG 2002. Strongyloides venezuelensis infection susceptibility of seven inbred strains of mice. Arq Bras Med Vet Zootec 54: 273-278.

Concha R, Harrington W Jr, Rogers AI 2005. Intestinal strongyloidiasis: recognition, management and determinants of outcome. J Clin Gastroenterol 39: 203-211.

Dorris M, Viney ME, Blaxter ML 2002. Molecular phylogenetic analysis of the genus Strongyloides and related nematodes. Int J Parasitol 32: 1507-1517.

Dreyer G, Fernandes-Silva E, Alves S, Rocha A, Albuquerque R, Addis D 1996. Patterns of detection of Strongyloides stercoralis in stool specimens: implications for diagnosis and clinical trials. J Clin Microbiol 34: 2569-2571.

Evering T, Weiss LM 2006. The immunology of parasite infections in immunocompromised hosts. Parasite Immunol 28: 549-565.

Gilioli R, Andrade LAG, Passos LAC, Silva FA, Rodrigues DM, Guaraldo AMA 2000. Parasite survey in mouse and rat colonies of Brazilian laboratory animal houses kept under different sanitary barrier conditions. Arq Bras Med Vet Zootec 52: 60-69.

Katz N, Chaves A, Pellegrino J 1972. A simple device for quantitative stool thick-smear technique in Schistosomiasis mansoni. Rev Inst Med Trop Sao Paulo 14: 397-400.

Kreike J, Lehner A 1995. Sex determination and DNA competition in the analysis of forensic mixed stains by PCR. Int J Legal Med 107: 235-238.

Liu LX, Weller PF 1993. Strongyloidiasis and other intestinal nematode infections. Infect Dis Clin North Am 7: 655-82.

Machado ER, Carlos D, Lourenço EV, Sorgi CA, Silva EV, Ramos SG, Ueta MT, Aronoff DM, Faccioli LH 2009. Counterregulation of Th2 immunity by interleukin 12 reduces host defenses against Strongyloides venezuelensis infection. Microbes Infect 11: 571-518.

Machado ER, Faccioli LH, Costa-Cruz JM, Lourenço EV, Roque-Barreira MC, Gonçalves-Pires Mdo R, Ueta MT 2008. Strongyloides venezuelensis: the antigenic identity of eight strains for the immunodiagnosis of human strongyloidiasis. Exp Parasitol 119: 7-14.

Machado ER, Ueta MT, Lourenço EV, Anibal FF, Roque-Barreira MC, Faccioli LH 2007. Comparison of immune response in mice infected with different strains of Strongyloides venezuelensis. Parasite Immunol 29: 549-557.

Nakai ES, Amarante AFT 2001. Experimental infection in mice (Mus musculus) and (Rattus norvegicus) by Strongyloides venezuelensis. Braz J Vet Parasitol 10: 1-6.

Oikarinen S, Tauriainen S, Viskari H, Simell O, Knip M, Virtanen S, Hyöty H 2009. PCR inhibition in stool samples in relation to age of infants. J Clin Virol 44: 211-214.
Pinto RM, Gonçalves L, Noronha D, Gomes DC 2001. Worm burdens in outbred and inbred laboratory rats with morphometric data on Syphacia muris (Yamaguti, 1935) Yamaguti, 1941 (Nematoda, Oxyuroidea). Mem Inst Oswaldo Cruz 96: 133-136.

Pontes LA, Oliveira MC, Katz N, Dias-Neto E, Rabello A 2003. Comparison of a polymerase chain reaction and the Kato-Katz technique for diagnosing infection with Schistosoma mansoni. Am J Trop Med Hyg 68: 652-656.

Rozen S, Skaletsky HJ 2000. Primer3 on the WWW for general users and for biologist programmers. In S Krawetz, S Misener, Bioinformatics methods and protocols: methods in molecular biology, Humana Press, Totowa, p. 365-386.

Sandoval N, Siles-Lucas M, Alban JL, Perez-Arellano JL, Garate T, Muro A 2006. Schistosoma mansoni: a diagnostic approach to detect acute schistosomiasis infection in a murine model by PCR. Exp Parasitol 114: 84-88.

Siddiqui AA, Berk SL 2001. Diagnosis of Strongyloides stercoralis infection. Clin Infect Dis 33: 1040-1047.

Steinmann P, Zhou XN, Du ZW, Jiang JY, Wang LB, Wang XZ, Li LH, Marti H, Utzinger J 2007. Occurrence of Strongyloides stercoralis in Yunnan Province, China and comparison of diagnostic methods. PLoS Negl Trop Dis 31: e75.

Taira N, Nakamura Y, Almeida MAO, Saeki H 1995. Massive experimental infection with Strongyloides venezuelensis in rats and absence of sudden death. J Vet Med Sci 57: 855-858.

Tamura N 1993. Studies on availability of Strongyloides venezuelensis for experimental model of strongyloidosis. Bul Nip Vet A Sci 59: 94-96.

Ueno H, Gonçalves PC 1998. Manual para diagnóstico das helmintoses de ruminantes, 4th ed., Japan International Cooperation Agency, Tokyo, 143 pp.

Uparanukraw P, Phongsri S, Morakote N 1999. Fluctuations of larval excretion in Strongyloides stercoralis infection. Am J Trop Med Hyg 60: 967-973.

Vadlamudi RS, Chi DS, Krishnaswamy G 2006. Intestinal strongyloidiasis and hyperinfection syndrome. Clin Mol Allergy 4: 8.

Verweij JJ, Canales M, Polman K, Ziem J, Brienen EA, Polderman AM, van Lieshout L 2009. Molecular diagnosis of Strongyloides stercoralis in fecal samples using real-time PCR. Trans $R$ Soc Trop Med Hyg 103: 342-346.

Weiss JB 1995. DNA probes and PCR for diagnosis of parasitic infections. Clin Microbiol Rev 8: 113-130.

Wongratanacheewin S, Pumidonming W, Sermswan RW, Maleewong W 2001. Development of a PCR-based method for detection of Opisthorchis viverrini in experimentally infected hamsters. Parasitology 122: 175-180. 